\title{
STRATEGI PENGEMBANGAN AGRIBISNIS HOLTIKUTURA PADA LEMBAGA MANDIRI YANG MENGAKAR DI MASYARAKA (LM3)
}

\author{
Ekaria* \\ Staf Pengajar FAPERTA UMMU-Ternate, Email: ekaria.chan@yahoo.co.id
}

\begin{abstract}
ABSTRAK
Lembaga mandiri yang mengakar di masyarakat (LM3) adalah lembaga yang tumbuh di tengah masyarakat dan telah berperan dalam pembinaan dan pengembangan sosial ekonomi masyarakat, khususnya di bidang pertanian. Tujuan penelitian ini adalah untuk mengidentifikasi faktor-faktor lingkungan internal dan eksternal yang dapat mempengaruhi LM3 dan merumuskan strategi pengembangan usaha yang dapat diterapkan oleh LM3. Metode yang digunakan dalam penelitian ini adalah deskriptif, sedangkan analisis yang digunakan dalam menentukan strategi adalah dengan analisis SWOT. Hasil penelitian diperoleh: 1) faktor-faktor eksternal yang merupakan peluang adalah tersedianya sarana transportasi untuk pemasaran, informasi pasar, tersediannya dana pengembangan LM3 dari Kementrian Pertanian RI, adanya kemitraan dengan instansi, sedankan ancaman yaitu banyannya produk holtikultura yang didatngkan dari luar daerah merupakan ancaman bagi LM3 dan adanya persaingan harga. 2) Faktor-faktor internal yang merupakan kekuatan adalah LM3 memiliki modal yang cukup, ketersedian lahan pertanian, tenaga kerja yang trampil, produk/panen yang stabil, sedangkan kelamahan yaitu penguasaan teknologi di LM3 masih rendah merupakan kelamahan LM3, sulitnya pengadaan bibit yang besertifikat/berkualitas, dan kurangnya ketersediaan pupuk. 3) Perencanaan strategis yang dapat dilakukan yaitu meningkatkan produktivitas panen, melakukan penjadwalan sistem tanam dan bekerjasama dengan Dinas Pertanian dalam melakukan kegiatan pengembangan dan pelatihan sehingga dapat memenuhi permintaan pasar.
\end{abstract}

Kata Kunci : Strategi, Pengembangan Agribisnis, LM3

\section{PENDAHULUAN}

1.1. Latar Belakang

Lembaga mandiri yang mengakar di masyarakat (LM3) adalah lembaga yang tumbuh di tengah masyarakat dan telah berperan dalam pembinaan dan pengembangan sosial ekonomi masyarakat. Berdasarkan surat keputusan Menteri Pertanian No.555/Kpts/OT.210/6/97 dan surat Sekretaris Jenderal, Departemen Pertanian No. RC.220/720/B/VI/1998 tentang pengembangan agribisnis LM3, yang dimaksud dengan LM3 berbasis keagamaan meliputi ; pondok pesantren, seminari, paroki, pasraman, vihara dan subak. Pengembangan LM3 terutama Pondok Pesantren dalam pengembangan pertanian (agribisnis) semakin bergulir dengan cakupan komoditas, kegiatan, institusi dan areal yang lebih luas.

Kota Tidore Kepulauan merupakan salah satu penerima dana bantuan LM3 terpilih pada tahun 2012, berasal dari Pondok Pesantren (ponpes) Harisul Khairaat Bumi Hijrah Tidore dengan mengembangkan agribisnis holtikultura dan tanaman pangan yang dijadikan target pengembangan karena sasaran yang ingin dicapai adalah pemenuhan kebutuhan pangan/kebutuhan pokok secara mandiri dan diharapkan menjadi agen perubahan pertanian tanaman pangan dan holtikultura serta merangsang tumbuhnya usaha agribisnis dan agroindustri di 
lingkungan ponpes. Tanaman pangan dan holtikultura yang dikembangkan yaitu tanaman jagung, mangga dan rambutan.

Dalam pengembangan agribisns holtikultura LM3 telah mengalamibanyak kendala dantantangan. Banyaknya komoditi holtikultura yang dipasarkan di Kota Ternate sebagai pusat perdagangan di Maluku Utara, membuat pihak LM3 mengalami kesulitan tersendiri. Melihat situasi ini strategi pengembangan LM3 agar tetap bertahan dan berkembang sangat dibutuhkan, terlebih lagi posisi LM3 yang terus mengalami kemajuan pada aspek produksinya.

1.2. Tujuan Penelitian

1). Sebagai informasi dan bahan pertimbangan dalam pengembangan agribisnis holtikultura

2). Dapat menjadi masukan dalam penyusunan kebijakan teknis bagi Dinas Pertanian yang berkenaan dengan pengembangan agribisnis holtikultura

\section{METODE PENELITIAN}

\subsection{Lokasi dan Waktu Penelitian}

Penelitian berlangsung selama dua bulan; November hingga Desember 2016.Penentuan lokasi dilakukan secara sengaja. Menurut Singarimbun dan Effendi (1995), penentuan lokasi secara sengaja (purposive) yaitu dengan cara memilih daerah penelitian berdasarkan ciri-ciri atau alasan yang dipandang mempunyai hubungan dengan permasalahan yang diteliti. Penelitian ini dilakukan di Pondok Pesantren Harisul Khairaat Bumi Hijrah Kota Tidore Kepulauan yang merupakan salah satu ponpes di Kota Tidore Kepulauan yang menerima bantuan dana dari program Lembaga Mandiri yang Mengakar di Masyarakat (LM3). Jenis usaha yang dikembangkan yaitu sub sektor agribisnis holtikultura.

Jenis dan Sumber Data

Jenis data yang diperlukan bagi penelitian ini dapat dipilah dalam kategori data primer dan data sekunder. Data primer berupa hasil pengisian kuesioner dengan cara mencatat hasil wawancara dengan responden yang meliputi informasi tentang karakteristik responden, defenisi LM3, sejarah LM3, strategi operasional, komponen kegiatan, sasaran kegiatan dan indikator keberhasilan. Data sekunder berupa data yang didapatkan dari BPS (Badan Pusat Statistik) dan data dari Departemen Pertanian yang terkait dengan penelitian.

\subsection{Metode Pengumpulan Data dan Jumlah Responden}

Metode pengumpulan data yang digunakan yaitu wawancara dan dokumentasi.Penentuan responden dilakukan secara sengaja (purposive).Responden dipilih dari pihakpihak internal dan eksternal LM3 yang berkompeten dan memahami perkembangan LM3. Responden dari pihak internal yaitu pemilik/pimpinan dan coordinator pemasaran dari LM3, karena kedua responden tersebut merupakan pengambil keputusan dalam menetapkan strategi yang akan dijalankan dalam kegiatan usahanya. Responden dari pihak eksternal yaitu Badan Pelaksana Penyuluhan Pertanian, Peternakan dan Kehutanan (BP4K) dan Dinas Pertanian. Responden dari BP4K dan Dinas Pertanian dipilih karena melakukan pendampingan dan pengawasan di LM3 dalam proses produksi maupun pemasarannya.

\subsection{Metode Analisis Data}

Analisis SWOT bertujuan menganalisis potensi/kekuatan, kelemahan, peluang dan ancaman yang dihadapi dalam pengembangan usaha agribisnis holtikultura di Ponpes Harisul Khairaat Bumi Hijrah Kota Tidore Kepulauan.Kekuatan dan kelemahan merupakan faktor internal, sedangkan peluang dan ancaman merupakan faktor eksternal.Analisis SWOT digunakan untuk mengidentifikasi berbagai faktor secara sistematik untuk merumuskan strategi kegiatan.Analisis digunakan untuk memaksimalkan kekuatan (strength), peluang (opportunities), serta meminimalkan kelemahan (weaknesses) dan ancaman (threats). Proses pengambilan keputusan selalu berkaitan dengan pengembangan misi, tujuan, strategi, dan kebijakan. Dengan demikikan, perencanaan strategis harus menganalisis faktor-faktor strategi kegiatan (kekuatan, kelemahan, peluang, dan ancaman) sesuai dengan kondisi saat ini (Rangkuti, 1997). 


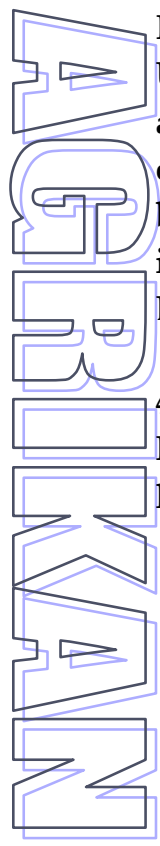

IV. HASIL DAN PEMBAHASAN

Untuk menemukan strategi pengembangan agribisnis holtikultura maka diidentifikasikan empat komponen analisis SWOT yang meliputi berbagai kekuatan dan kelemahan (Faktor internal), peluang dan ancaman (Faktor Eksternal).

\subsection{Analisis Faktor Internal}

Faktor-faktor internal yang merupakan kekuatan bagi LM3, yaitu LM3 memiliki modal untuk mengembangkan potensi usahanya, ketersediaan lahan pertanian, tenaga kerja yang terampil, dan produksi yang stabil.Faktorfaktor internal yang merupakan kelemahan bagi LM3, yaitu penguasaan teknologi yang masih rendah, sulitnya pengadaan bibit yang berkualitas dan kurangnya ketersediaan pupuk.Dengan memasukkan hasil identifikasi kekuatan dan kelemahan sebagai faktor internal, kemudian diberi bobot dan peringkat, disajikan pada Tabel 1.

Tabel 1. Bobot dan Peringkat Faktor Internal (Kekuatan dan Kelemahan)

\begin{tabular}{|c|c|c|c|}
\hline Faktor Strategis Internal & Bobot & Peringkat & Skor \\
\hline \multicolumn{4}{|l|}{ Kekuatan (Stregths) } \\
\hline LM3 memiliki modal yang cukup & 0,14 & 4 & 0,56 \\
\hline Ketersediaan lahan pertanian & 0,17 & 4 & 0,68 \\
\hline Tenaga kerja yang terampil & 0,14 & 3,3 & 0,46 \\
\hline Produksi yang stabil & 0,16 & 3,3 & 0,53 \\
\hline \multicolumn{4}{|l|}{ Kelemahan (Weaknesses) } \\
\hline Penguasaan teknologi masih rendah & 0,11 & 3,3 & 0,36 \\
\hline Sulitnya pengadaan bibit yang berkualitas & 0,14 & 1,3 & 0,18 \\
\hline Kurangnya ketersediaan pupuk & 0,14 & 2,3 & 0,32 \\
\hline Total & 1 & & 3,09 \\
\hline
\end{tabular}

Faktor internal strategis yang menjadi kekuatan bagi LM3 yaitu ketersediaan lahan pertanian dengan skor tertinggi 0,68 dan faktor internal yang merupakan kelemahan terbesar yaitu sulitnya pengadaan bibit yang berkualitas dengan nilai skor 0,18. Kerjasama yang baik dengan Dinas Pertanian sangat di perlukan untuk meningkatkan kualitas hasil panen dengan bibit yang berkualitas. Total skor yang diperoleh berada pada rata-rata yaitu sebesar 3,09 mengindikasikan posisi internal LM3 cukup kuat karena telah memanfaatkan kekuatan yang dimiliki untuk meminimalisasi kelemahannya.

\subsection{Analisis Faktor Eksternal}

Faktor-faktor eksternal yang merupakan peluang bagi LM3, yaitu Tersedianya sarana transportasi untuk pemasaran sangat mudah dan lancer pada daerah konsumen, adanya informasi pasar, tersedianya dana pengembangan LM3 dari Kementrian Pertanian RI, adanya pola kemitraan dengan instansi. Faktor-faktor eksternal yang merupakan ancaman bagi LM3, yaitu banyaknya produk holtikultura yang didatangkan dari luar daerah dan adanya persaingan harga mengingat produk holtikultura pada umumnya mudah rusak.Dengan memasukkan hasil identifikasi peluang dan ancaman sebagai factor eksternal, kemudian diberi bobot dan peringkat, disajikan pada Tabel 2.

Tabel 2. Bobot dan Peringkat Faktor Eksternal ( Peluang dan Ancaman

\begin{tabular}{lccc}
\hline Faktor Strategis Eksternal & Bobot & Peringkat & Skor \\
\hline Peluang (Opportunities) & & & \\
\hline Tersedianya sarana transporasi & 0,19 & 3 & 0,57 \\
Tersedianya informasi pasar & 0,15 & 2,7 & 0,40 \\
Tersedianya dana pengembangan LM3 & 0,19 & 4 & 0,76 \\
Adanya kemitraan dengan instansi & 0,19 & 3 & 0,57 \\
\hline Ancaman (Threats) & & & \\
\hline Banyaknya produk holtikultura dari luar daerah & 0,12 & 3,3 & 0,40 \\
Adanya persaingan harga & 0,16 & 2,7 & 0,43 \\
\hline Total & 1 & & 3,13 \\
\hline
\end{tabular}


Faktor eksternal yang merupakan peluang terbesar dan paling berpengaruh bagi LM3 adalah tersedianya dana pengembangan LM3 dari Kementrian Pertanian RI dengan skor tertinggi yaitu 0,76. Faktor eksternal yang menjadi ancaman bagi LM3 adalah adanya persaingan harga dengan skor tertinggi yaitu 0,43 . Total skor yang diperoleh yaitu 3,13, mengindikasi bahwa LM3 merespon dengan baik terhadap peluang dan ancaman dalam pengembangan agribisnisn holtikultura karena mengambil keuntungan dari peluang yang ada saat ini dan meminimalkan efek yang mungkin muncul.


Tabel 3. Matriks Analisis SWOT Pengembangan Agribisnis Holtikultura

\begin{tabular}{|c|c|c|}
\hline & $S$ & $\mathbf{W}$ \\
\hline O & $\begin{array}{l}\text { Strategi S-O : } \\
\text { 1. Memperluas pasar dengan meningkatkan } \\
\text { volume penjualan. } \\
\text { 2. Meningkatkan produktivitas panen } \\
\text { holtikultura dengan melakukan } \\
\text { pengajuan dana pengembangan LM3 di } \\
\text { Kementrian Pertanian RI. } \\
\text { 3. Membangun kemitraan yang kuat } \\
\text { dengan Dinas Pertanian dan Penyuluh } \\
\text { pertanian. }\end{array}$ & $\begin{array}{l}\text { Strategi W-O: } \\
\text { 1. Mengadakan pelatihan untuk } \\
\text { pengelola LM3 dengan kerjasama dari } \\
\text { penyuluh pertanian. } \\
\text { 2. Mengajukan permohonan bantuan } \\
\text { bibit dan pupuk kepada Dinas } \\
\text { Pertanian. }\end{array}$ \\
\hline $\mathbf{T}$ & $\begin{array}{l}\text { Strategi S-T: } \\
\text { Melakukan penjadwalan system tanam. }\end{array}$ & $\begin{array}{l}\text { Strategi } \mathrm{W}-\mathrm{T} \text { : } \\
\text { Berkerjasama dengan Dinas Pertanian } \\
\text { dan Penyuluh Pertanian dalam } \\
\text { melakukan kegiatan pengembangan dan } \\
\text { pelatihan. }\end{array}$ \\
\hline
\end{tabular}

Strategi SO adalah strategi yang menggunakan kekuatan internal LM3 untuk memanfaatkan peluang eksternal, dimana kekuatan internal dapat memanfaatkan tren dan kejadian internal. Strategi yang dapat digunakan yaitu memperluas pasar dengan meningkatkan volume penjualan, meningkatkan produktivitas panen holtikultura dengan melakukan pengajuan dana pengembangan LM3 di Kementrian Pertanian RI, dan membangun kemitraan yang kuat dengan Dinas Pertanian dan Penyuluhan Pertanian.

Strategi WO bertujuan untuk memperbaiki kelemahan internal dengan
4.3. Strategi pengembangan agribisnis holtikultura

Pengembangan agribisnis holtikultura memerlukan perubahan strategi dan program yang diperlukan berdasarkan tingkat kepentingan. Perubahan strategi ditetapkan berdasarkan peringkat untuk keempat komponen SWOT. Strategi agresif (S-O) digunakan memaksimalkan kekuatan untuk meraih peluang secara optimal, strategi diversifikasi/ubah strategi (W-O) digunakan untuk meminimalkan kelemahan untuk meraih peluang semaksimal mungkin, strategi divestasi (S-T) digunakan memaksimalkan kekuatan untuk mengurangi ancaman yang ada, dan strategi bertahan (W-T) digunakan meminimalkan kelemahan dan hambatan untuk meminimalkan ancaman (Taufik, 2002). Strategi pengembangan disajikan pada Tabel 3. memanfaatkan peluang eksternal. Strategi yang dapat digunakan LM3 adalah mengadakan pelatihan untuk mengolah LM3 dengan kerjasama dari penyuluhan pertanian dengan mengajukan permohonan bibit dan pupuk yang berkualitas untuk menjaga kontinuitas produksi sehingga dapat mengembangkan wilayah pemasaran.

Strategi ST adalah strategi yang menggunakan kekuatan LM3 untuk menghindari atau mengurangi pengaruh dari ancaman eksternal. Strategi yang dapat digunakan oleh LM3 yaitu dengan melakukan penjadwalan system tanam untuk memprediksi 


kebutuhan pasar sehingga LM3 dapat
menghindari ancaman dari luar.
Strategi WT adalah taktik desensif yang
diarahkan pada pengurangan kelemahan
internal dan menghindari ancaman eksternal.
Strategi yang dapat digunakan oleh LM3 adalah
melakukan kegiatan penelitian dan
pengembangan terhadap produk yang
dihasilkan untuk dapat bersaing dengan
komoditi holtikultura yang didatangkan dari
luar daerah Maluku Utara. Penelitian dan
pengembangan dapat dilakukan melalui
kerjasama antara LM3 dengan instansi
pemerintah ataupun dengan instansi
pendidikan untuk dapat menghasilkan produk
Lang bervariasi (diversifikasi produk).Sehingga
LM3 dapat meminimalisasi kelemahan yang
dimiliki dan menghindari ancaman dari
lingkungan eksternal.

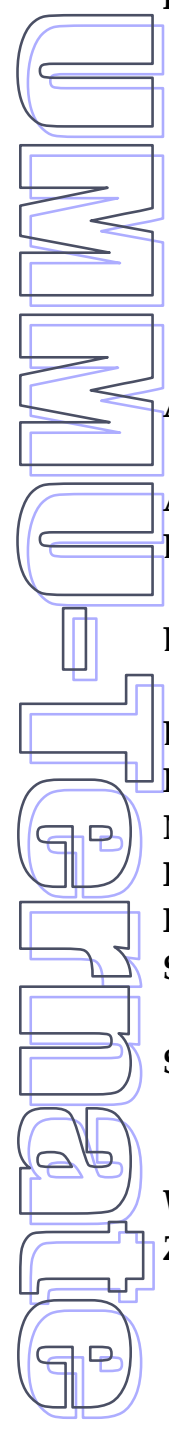
Udayana.

Departemen Pertanian, 2009. Kemitraan dan Negoisasi. Jakarta. No.1/Feb. 2000, 1-9.
IV. KESIMPULAN DAN SARAN

\subsection{Kesimpulan}

Perencanaan strategi yang dapat dilakukan oleh LM3 yaitu meningkatkan produkvitas panen, melakukan penjadwalan system tanam dan bekerjasama dengan Dinas Pertanian dalam melakukan kegiatan pengembangan dan pelatihan sehingga dan memenuhi permintaan pasar.

\subsection{Saran}

1. Dalam mengatasi ancaman dan kelemahan yang ada, LM3 harus menjalin kemitraan dengan instansi terkait dalam hal ini BP4K dan Dinas Pertanian, sehingga dapatt dapat memenuhi permintaan pasar.

2. Strategi selanjutnya yang harus dipriotaskan oleh LM3 yaitu melakukan kegiatan penelitian dan pengembangan terhadap produk yang dihasilkan untuk dapat bersaing dengan komuniti holtikultura yang didatangkan dari luar daerah Maluku Utara.

\section{DAFTAR PUSTAKA}

Antara, Made. 2010. Bahan Ajar Metodelogi Penelitian Sosial. Fakultas Pertanian, Universitas

Arikunto, Suharsimi. 2010. Prosedur Penelitian. Edisi Revisi. Jakarta: Rineka Cipta.

Departemen Pertanian, 2009. Pedoman Pemberdayaan dan Pengembangan Usaha Agribisnis Lembaga Mandiri yang Mengakar di Masyarakat (LM3).

Departemen Pertanian, 2009. Pemberdayaan dan Pengembangan Usaha Agribisnis Holtikultura untuk Lembaga Mandiri yang Mengakar di Masyarakat (LM3).

Kusnadi, 2000. Pembangunan Masyarakat Pedesaan, Gramedia Pustaka Utama. Jakarta.

Nasution, 2004. Teori dan Konsep Pembangunan Ekonomi, Gramedia Pustakaindo, Jakarta.

Profil LM3 Pondok Pesantre Haritsul Khairaat Bumi Hijrah Tidore.

Rangkuti, F. 1997. Analisis SWOT Teknik Membedah Kasus Bisnis. Gramdedia, Jakarta.

Singarimbun dan Effendi, 1995. Metode Penelitian untuk Skripsi. PT. Raja Griffindo Persada.

Siragih, Bungaran, 2000. Agribisnis Sebagai Landasan Pembangunan Ekonomi Indonesia Dalam Era Millenium Baru. Jurnal Studi pembangunan, Kemasyarakatan \& Lingkungan, Vol 2,

Wikipedia, 2010. Agribisnis. Http://id.wikipedia.org/wiki/Agribisnis.

Zulkarnain, 2010. Dasar-dasar Holtikultura. Bumi Aksara, Jakarta. 